\title{
Определение влаги и примесей в трансформаторном масле модифицированным методом Фишера
}

И.Д. Гиззатова, В. К. Козлов, д. ф.-М.Н., Д. М. Валиуллина, К. Т.Н., УдК 621.315.615 Казанский государственный энергетический университет, Казань Р.А. Гиниатуллин, К. Т. Н., Казанский национальный исследовательский технологический университет, Казань

\begin{abstract}
Рассмотрен модифицированный метод Фишера для определения абсолютного содержания влаги и количества примесей в трансформаторном масле. Представлены результаты, полученные после вакуумной осушки, охлаждения и обработки сверхвысокочастотным излучением. Показано, что все три способа помогают полностью удалить влагу из масла, а затем оценить количество других примесей. Обсуждаются преимущества предложенного метода и возможности его применения для определения состава примесей.
\end{abstract}

Известно, что в ходе эксплуатации трансформаторов происходит ухудшение электроизоляционных свойств и старение масла. В нем происходят различные физико-химические процессы, протекающие под воздействием температуры, электромагнитных полей, кислорода и т.д. Процесс старения ускоряется при повышении температуры, увеличении концентрации окисленных форм углеводородов и влагосодержания. Все эти факторы однонаправленного действия и в различной степени приводят к изменению физикохимических свойств жидкой изоляции и, прежде всего, диэлектрических характеристик, которые определяют ее эксплуатационную пригодность [1, 2].

С точки зрения сохранения эксплуатационной надежности и ресурса силового трансформатора влагосодержание изоляции является важнейшим и наиболее опасным показателем. Один из химических методов его высокоточного определения - кулонометрическое титрование по Карлу Фишеру. Однако он имеет свои недостатки и неприменим для окислившихся масел, так как в процессе их старения, кроме воды, образуются перекиси, низкомолекулярные водорастворимые одноосновные кислоты (муравьиная, уксусная, пропионовая, масляная и др.), жирные одноосновные и двухосновные высокомолекулярные кислоты, нафтеновые, асфальтогеновые, а также оксикислоты, фенолы, спирты, альдегиды, кетоны [3].

Процесс старения масла проходит несколько этапов. Начальный - индукционный период, в течение которого не наблюдается заметных изменений. В зависимости от особенностей химического состава масла продолжительность индукционного этапа может варьироваться в широких пределах. Следующий - период самоускорения реакции - вызван, в основном, распадом образовавшихся гидроперекисей на радикалы. Затем начинается период постоянной скорости процесса, в котором скорости образования и гибели свободных радикалов равны. На этом этапе образуются продукты окисления (фенольного типа), способные тормозить старение. Когда концентрация этих продуктов достигает определенной величины, наступает период самоторможения. В начале окисления трансформаторных масел, вскоре после индукционного периода образуются в первую очередь низкомолекулярные кислоты и фенолы. Содержание растворимых низкомолекулярных кислот составляет 30-50\% от общего количества кислот $[4,5]$.

Реактив Фишера взаимодействует с продуктами окисления, содержащими группу ОН.

Таким образом, для правильного определения влаги в масле необходимо учитывать:

- кислотность среды, то есть кислоты и основания, образующиеся в ходе эксплуатации трансформаторного масла;

- присутствие в эксплуатационном масле соединений, например альдегидов и кетонов, вступающих в реакцию с метанолом с выделением воды [6]. 


\section{ЭКСПЕРИМЕНТАЛЬНАЯ ЧАСТЬ}

Для исключения влияния примесей на определение влагосодержания и удаления растворенной воды предложена модернизация метода Фишера и собрана экспериментальная установка вакуумной осушки трансформаторного масла, которая состоит из кулонометрического титратора 831 КФ Coulometer компании Metrohm (Швейцария) и вакуумного насоса. Трансформаторное масло (100 г) в колбе подогревается до температуры $100{ }^{\circ} \mathrm{C}$. С помощью вакуумного насоса (Р=2 мм рт.ст.), подсоединенного к колбе, создается вакуум, и отводится влага. Колба равномерно непрерывно подогревается в течение всего эксперимента, через равные промежутки времени из нее отбирают осушенное масло и определяют его влагосодержание с помощью кулонометрического титратора (масса внесенной пробы масла в прибор - 10 г).

Природа происхождения примесей - не известна, поэтому их нельзя удалить из отработанного трансформаторного масла. Но можно определить влагосодержание до вакуумной осушки и после нее. Разница между этими измерениями определяет содержание воды в масле без влияния примесей [7].

На установке проведены исследования по выявлению зависимости содержания влаги в процессе вакуумной осушки в чистом трансформаторном масле от времени. Определено время вакуумной осушки для удаления влаги (с учетом диапазона измерения прибора) из трансформаторного масла - оно составило 30 мин [7].

Для определения примесей, образовавшихся в отработанном масле, и получения абсолютного числа влагосодержания мы измерили количество воды в масле до и после вакуумной осушки. Таким образом, после осушки определили количество примесей, вступивших в реакцию с реактивом Фишера.

Разность между показанием прибора до и после осушки определяет абсолютное влагосодержание. Опыт проводили на семи образцах масла. Данные исследования представлены в табл. 1.

На следующем этапе изучали процесс охлаждения масла. Известно, что один из способов удаления воды из масла заключается в его выдерживании при отрицательных температурах. В качестве контроля охлаждали чистое трансформаторное масло. Сначала определили влагу до охлаждения с помощью кулонометрического титратора 831 КФ Coulometer, а затем образец поместили в морозильную камеру при температуре $-18^{\circ} \mathrm{C}$ и выдержали его в течение 12 ч. Влагосодержание до охлаждения составило 19,8 ppm, а после прибор показал значение близкое к нулю (2 ppm).

При охлаждении выделившиеся микрокристаллы воды начинают образовывать сетчатые каркасные структуры, увеличивая вязкость масла. Косвенно можно оценить содержание в нем воды, например, чем ниже температура помутнения, тем воды меньше. Так как льдинки тяжелее масла, они
Таблица 1. Результаты определения влагосодержания в образцах трансформаторного масла методом осушки

\begin{tabular}{|c|c|c|c|c|c|c|c|}
\hline \multirow[t]{2}{*}{ Показатель } & \multicolumn{7}{|c|}{ № образца } \\
\hline & 1 & 2 & 3 & 4 & 5 & 6 & 7 \\
\hline $\begin{array}{l}\text { Влагосодержа- } \\
\text { ние до осушки, } \\
\text { ррm }\end{array}$ & 6,8 & 9,8 & 6,5 & 1,3 & 7,7 & 3,1 & 4,5 \\
\hline $\begin{array}{l}\text { Влагосодержа- } \\
\text { ние после осуш- } \\
\text { ки (количество } \\
\text { примесей), ppm }\end{array}$ & 4,8 & 3 & 3,2 & 1,0 & 6,2 & 2,3 & 0,3 \\
\hline $\begin{array}{l}\text { Абсолютное } \\
\text { влагосодержа- } \\
\text { ние, рpm }\end{array}$ & 2 & 6,8 & 3,3 & 0,3 & 1,5 & 0,8 & 4,2 \\
\hline
\end{tabular}

оседают на дно. Таким образом, после охлаждения вода кристаллизуется и можно отобрать сухое масло, в котором влага полностью удалена.

Эксперимент провели с четырьмя образцами отработанного трансформаторного масла с разных подстанций (ПС): образец 1 - ПС Константиновка, образец 2- ПС Заречье, образец 3 - ПС Азино, образец 4 - ПС Водозабор. В табл. 2 приведены результаты определения влагосодержания до и после охлаждения. До охлаждения прибор показывает суммарное значение влаги и примесей, после охлаждения - определяет только количество примесей, так как вода удалена и реактив взаимодействует с оставшимися окисленными формами примесей.

Важное влияние на равновесие различных форм воды в масле оказывает температура. Температура среды - энергетический фактор, который влияет на прочность связей молекул воды с различными компонентами масла и между собой. При повышении температуры эти связи ослабевают,

Таблица 2. Результаты экспериментального исследования образцов трансформаторного масла методом охиаждения

\begin{tabular}{|l|c|c|c|c|}
\hline \multirow{2}{*}{ Показатель } & \multicolumn{4}{|c|}{ № образца } \\
\cline { 2 - 5 } & 1 & 2 & 3 & 4 \\
\hline $\begin{array}{l}\text { Влагосодержа- } \\
\text { ние до охлажде- } \\
\text { ния, ррт }\end{array}$ & 32,8 & 31,3 & 30,6 & 27,4 \\
\hline $\begin{array}{l}\text { Влагосодер- } \\
\text { жание после } \\
\text { охлаждения } \\
\text { (количество } \\
\text { примесей), ррт }\end{array}$ & 15,2 & 12,2 & 18,8 & 17,7 \\
\hline $\begin{array}{l}\text { Абсолютное } \\
\text { влагосодержа- } \\
\text { ние, ррт }\end{array}$ & 17,6 & 19,1 & 11,8 & 9,7 \\
\hline
\end{tabular}


Таблица 3. Результаты экспериментального исследования образцов трансформаторного масла методом обработки СВЧ-излучением

\begin{tabular}{|l|c|c|c|c|}
\hline \multirow{2}{*}{ Показатель } & \multicolumn{4}{|c|}{ № образца } \\
\cline { 2 - 5 } & 1 & 2 & 3 & 4 \\
\hline $\begin{array}{l}\text { Влагосодержание до обра- } \\
\text { ботки СВЧ-излучением, ppm }\end{array}$ & 32,8 & 31,3 & 30,6 & 27,4 \\
\hline $\begin{array}{l}\text { Влагосодержание после } \\
\text { обработки СВЧ-излучением } \\
\text { (количество примесей), ррm }\end{array}$ & 14,9 & 13,0 & 18,6 & 16,8 \\
\hline $\begin{array}{l}\text { Абсолютное влагосодержа- } \\
\text { ние, ррт }\end{array}$ & 17,9 & 18,3 & 12,0 & 10,6 \\
\hline
\end{tabular}

что приводит к увеличению содержания в масле растворенной воды.

В работе также исследовали свойства трансформаторного масла при его нагревании: образцы подвергали сверхвысокочастотному излучению (СВЧ) в микроволновой печи ( $\mathrm{P=1000} \mathrm{ВТ)} \mathrm{в} \mathrm{течение} 40$ мин. Для нагрева масла под действием электромагнитных волн необходимо присутствие в нем дипольных молекул, например, воды. Этим обусловлен выбор обработки трансформаторного масла именно СВЧ-излучением .

В процессе эксперимента температура масла увеличилась, следовательно вода в нем испарилась. Результаты измерения влагосодержания трансформаторного масла до обработки СВЧ-излучением и после приведены в табл. 3.

В качестве контроля обработке СвЧ-излучением подвергалось чистое трансформаторное масло без примесей. Влагосодержание до обработки составляло около 20 ppm, после - около 2 ррm.

Сравнивая данные табл. 1-3, можно сделать вывод о том, что методы вакуумной осушки, охлаждения и обработки СВЧ-излучением исключают влияние мешающих компонентов на результаты измерения влагосодержания трансформаторного масла.

Таким образом, удаление влаги из трансформаторного масла возможно тремя способами: вакуумной осушкой, охлаждением и обработкой СВч-излучением.

Также нами была получена зависимость содержания примесей в трансформаторном масле от кислотного числа (рис. 1).

Мерой всех кислот является кислотное число. По мере накопления в масле кислых соединений образуются продукты глубокого окисления - осадок, нерастворимый в масле. В зависимости от углеводородного состава трансформаторного масла количество осадка может быть различным. В эксплуатационных условиях в трансформаторах осадок начинает образовываться, как правило, когда кислотное число превышает 0,2-0,3 мг КОН на 1 г масла. Так как кислотное число отражает общее содержание примесей

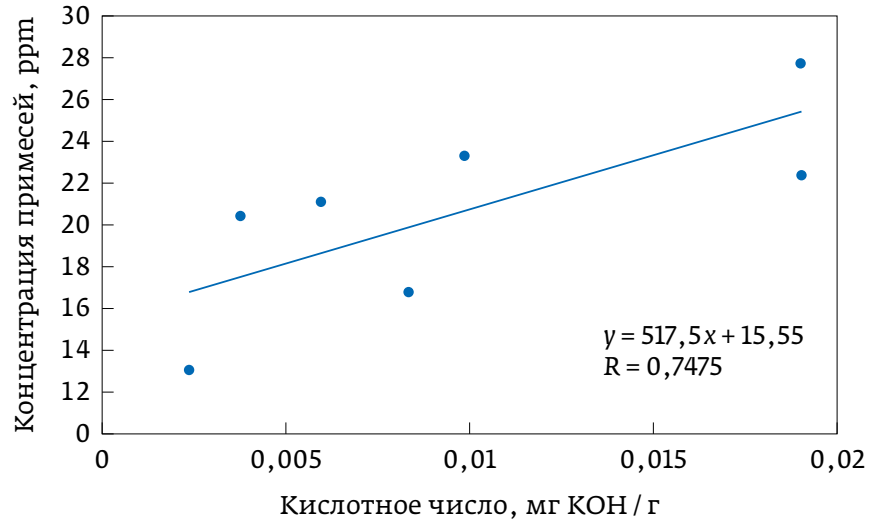

Puc. 1. Зависимость количества примесей от кислотного числа

в масле, исследована зависимость количества примесей (из табл. 1) от него. Измерение кислотного числа проводили в лаборатории филиала ОАО “Сетевая компания" Казанские электрические сети.

Полученная зависимость содержания примесей в трансформаторном масле от кислотного числа выражается следующим уравнением $y=517,5 x+15,5$. Как видно из рис. 1, чем выше кислотное число, тем больше примесей содержится в масле. Предельное максимальное значение кислотного числа для трансформаторов в эксплуатации установлено равным не более 0,25 мг КОН/г [8]. Таким образом, количество примесей коррелирует с кислотным числом и в маслах присутствуют допустимые концентрации простых кислот.

\section{выводы}

1. Кулонометрический метод определения влагосодержания в масле наиболее перспективен благодаря своей простоте, хорошей воспроизводимости, малому расходу токсичного реактива Фишера, доступности оборудования и реагентов. Кроме того, нет необходимости в стандартизации раствора. Недостаток метода в том, что образовавшиеся в отработанном масле примеси взаимодействуют с реактивом Фишера, искажая конечный результат.

2. Недостаток кулонометрического метода устранен путем вакуумирования, охлаждения и обработки масла СвЧ-излучением, так как этими способами удаляется вся растворенная вода.

3. Предложенный модифицированный метод Фишера позволяет определить количество примесей и абсолютное содержание влаги в масле после обработки одним из трех способов.

4. Получена зависимость количества примесей, содержащихся в эксплуатируемом трансформаторном масле от его кислотного числа, что позволяет в дальнейшем определить природу примесей. 


\section{ЛИТЕРАТУРА}

5. Липштейн Р.А., Шахович М.И.Трансформаторное масло. М.: Энергоатомиздат, 1983. 296 с.

6. Лизунова С.Д., Лоханина А.К. Силовые трансформаторы. Справочная книга под ред. Лизунова С. Д., Лоханина А. К. М: Энергоиздат, 2004. 616 с.

7. Колушев Д.Н., Широков А. В., Ротберт И.Л., Козлов В. К. Контроль влагосодержания изоляции силовых трансформаторов // Доклад [Электронный ресурс]. - Режим доступа: http://www.sibdiag.ru (Дата обращения: 25.12.2018)

8. Аракелян В.Г. Диагностика состояния изоляции маслонаполненного оборудования по влагосодержанию масла. Электротехника. 2004. № 3. C. 21.

9. Клюев В.В. Неразрушающий контроль и диагностика: Справочник 2-е изд., перераб. и доп. М.: Машиностроение, 2003. 656 с.

10. Митчел Дж., Смит Д. Акваметрия. М.: Издательство иностранной литературы, 1952. 424 с.

11. Козлов В.К., Загустина И. Д. Модифицированный метод определения влагосодержания трансформаторного масла // Известия высших учебных заведений. Проблемы энергетики. 2016. № 7-8. С. 87-90.

12. РД 34.43.105-89. Методические указания по эксплуатации трансформаторных масел. М., 1989. 52 с

\section{REFERENCES}

1. Lipshtein R.A., Shakhovich M. I. Transformer oil. M.: Energoatomizdat Publ. 1983. 296 p.

2. Lizunova S. D., Lokhanina A. K. Power transformers M: Energoizdat Publ. 2004. 616 p.

3. Kolushev D.N., Shirokov A.V., Rotbert I.L., Kozlov V.K. Insulation moisture control of power transformers. 25.12.2018. Available at: http://www.sibdiag.ru.

4. Arakelyan V.G. Diagnostics of the insulation condition of oil-filled equipment based on the moisture content of the oil // Electrical engineering - Elektrotekhnika. 2004. № 3. P. 21.

5. Клюев В. В. Moskva: Mashinostroenie Publ., 2003. 656 P

6. Mitchel Dzh., Smit D. Aquametry. M.: Izdatel"stvo inostrannoi literatury Publ. 1952. $424 \mathrm{p}$

7. Kozlov V. K., Zagustina I. D. Modified method for determining the moisture content of transformer oil // Proceedings of higher educational institutions. Energy problems. - Izvestiya vysshikh uchebnykh zavedenii. Problemy energetiki. 2016. № 7-8. Р. 87-90.

8. РД 34.43.105-89. Guidelines for the operation of transformer oils. М., 1989. 52 p.

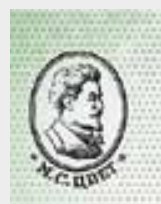

GSN 16800613
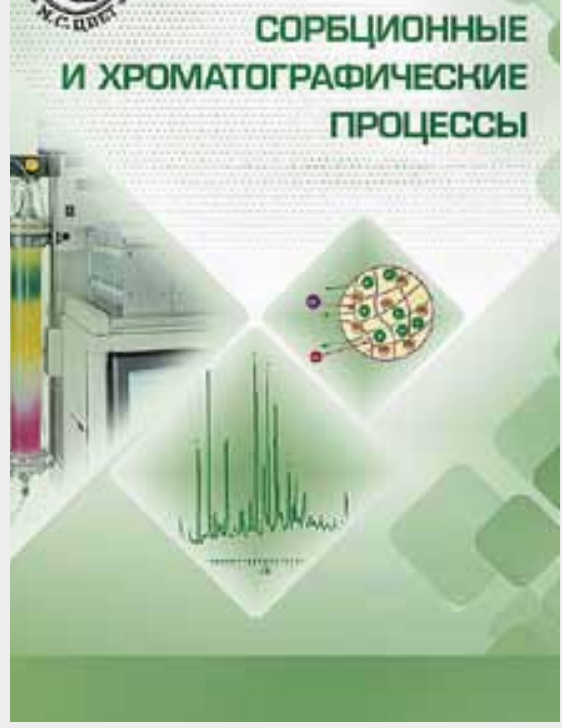

Вышел в свет очередной номер журнала "Сорбционные и хроматографические процессы", 2019, № 3, т. 19, ISSN1680-0613.

Журнап издается с 2000 года с периодичностью 6 раз в год и является преемником сборника "Теория и практика сорбционных процессов". Учредитель: Воронежский государственный университет. ГАввный редактор - профессор, д. х. н. Селеменев Виадимир Федорович.

\section{Содержание номера:}

Deineka V.I., Anh N.Van, Deineka L.A. Количественная взаимосвязь между структурой и удерживанием в обращенно-фазовой ВЭЖХ: расширенный инкрементный подход для предсказания удерживания триацилглицеринов

\section{Nikashina V. A.}

Проницаемые геохимические барьеры как способ защиты окружающей среды от загрязнений. Природные сорбенты для решения экологических задач. Математическое моделирование и расчет процессов. Обзор

Ryltsova I.G., Tarasenko E.A., Nestroinaia O.V., Lebedeva O.E. Сорбционные свойства MgCo / AlFe слоистых двойных гидроксидов

Poluektova V.A., Shapovalov N.A., Kozhanova E.P.

Изучение конкурентной адсорбции модификаторов на частицах полимерцементной системы для аддитивных технологий
Dampilova B.V., Zonkhoeva E.L. Равновесие и кинетика сорбции ионов лантана на природных цеолитах

Shinko E.I., Farafonova O.V. , Ermolaeva T.N., Shestopalov K.V. Активация углеродных нанотрубок для повышения эффективности аффинного взаимодействия на поверхности пьезоэлектрического сенсора при определении антибиотиков

Uvaysova S.M., Babuev M.A.

Определение условий модификации анионитов АН-31 и АРА-8п иммобилизацией 5-(4-карбоксифенил-азо)-роданина

Yashin Y.I., Lanin S.N., Kolomiets L.N., Buryak A.K.

Андрей Владимирович Киселев - ученый и общественный деятель

Yashin Y.I., Vedenin A.N., Yashin A.Ya. Портативные жидкостные хроматографы

Panarin V.Yu., Baum E.A., Lanin S.N. Появление первых теорий адсорбции в 20 веке 